\title{
Using Low-Calorie Orange Juice as a Dietary Alternative to Alkali Therapy
}

\author{
Tim Large, MD, James Williams Jr., PhD, John R. Asplin, MD, and Amy Krambeck, MD
}

\begin{abstract}
Purpose: The pursuit of a dietary source to increase urine $\mathrm{pH}$ and citrate in stone formers has been ongoing for $>30$ years. Early evidence showed that orange juice (OJ) contains alkali and citrate, but high sugar and ascorbic acid content limited the use of OJ as a viable daily source of alkali. Recently, novel low-calorie OJs have emerged and could potentially be a better option.

Methods: Beverages with high concentrations of alkali citrate and malate were identified using ion chromatography. Two low-calorie OJ beverages, in addition to crystal light lemonade beverage (CLLB), were chosen. Healthy volunteers $(5$ men, 5 women) drank $1 \mathrm{~L}$ of OJ or CLLB with $1 \mathrm{~L}$ water daily for 7 days, and then completed a 24-hour urinalysis. A washout week was instituted between trial weeks. The study design is a prospective randomized crossover control trial. A paired analysis using comparison of means was used to evaluate low-calorie OJ and CLLB. Volunteers had no prior history of kidney stones and maintained a journal with beverage compliance, side effect (SE), and dietary consumption data.

Results: Tropicana 50 (TRP50), Kroger low-calorie OJ (KLCO), and CLLB were found to have a total alkali content of 56.60, 47.9, and $17.3 \mathrm{mEq} / \mathrm{L}$, respectively, based on ion chromatography. Consumption of all three beverages raised urinary citrate (116.6 [ -118 to $373,177.9$ [ -3 to 359$], 155.6$ [ -4 to 237$] \triangle \mathrm{mg} /$ day $95 \%$ confidence interval) and urinary $\mathrm{pH}(0.25$ [0.08-0.53], 0.74 [0.41-1.07 $p<0.05], 0.25$ [0.25-0.64]), respectively, compared with water phase. Based on journal entries by volunteers, TRP50 had the most SEs (90\% participants) felt to be a result of the artificial sweetener (Stevia $\left.{ }^{\circledR}\right)$.

Conclusion: Low-calorie OJs, and to a lesser extent CLLB, have alkali and citrate based on ion chromatography. Daily consumption by healthy volunteers of KLCO can raise urinary pH.
\end{abstract}

Keywords: aciduria, hypocitraturia, dietary alternatives

\section{Introduction}

D IETARY ALTERNATIVES TO modify urinary derangements such as hypocitraturia or aciduria have been explored for $>30$ years. ${ }^{1}$ Low urinary citrate and $\mathrm{pH}$ can promote calcium oxalate and uric acid stone formation, respectively. The current American Urologic Association (AUA) guidelines state that potassium citrate (kcit) therapy should be initiated for patients with recurrent calcium stones and low urinary citrate, and uric acid or cystine stone formers with low urinary $\mathrm{pH}^{2}$ Unfortunately, compliance rates with kcit are poor because of gastrointestinal side effects (SEs), poor palatability, large pill size ${ }^{3}$ and cost. ${ }^{4}$ Rampant increases in the price of generic medications, such as kcit, occur when pharmaceutical companies obtain a market share of a drug's production or supply. ${ }^{5}$ This has been identified as a relatively new issue affecting kcit compliance rates.
There are multiple publications on dietary sources of alkali and citrate. Wabner and Pak published one of the earliest series in 1993 looking at orange juice (OJ) as an alternative source for citrate to prevent kidney stones. ${ }^{6}$ In addition, lemon-based beverages have been evaluated extensively in both bench ${ }^{7}$ and clinical settings. ${ }^{8-10}$ Changing urinary citrate and $\mathrm{pH}$ levels with concentrated lemon extract, lemonade, grapefruit, ${ }^{11}$ raspberry, and coconut juice ${ }^{12}$ have had mixed results. Despite early evidence that OJ harbored excellent alkali potential, valid concerns over the sugar content in $\mathrm{OJ}$, in combination with the promising bench results of concentrated lemon juice, led to a focused effort evaluating the efficacy of lemon-based beverages on urinary citrate and $\mathrm{pH}$ modulation. Eisner and colleagues published a summary of the alkali potential of multiple lemon-based beverages. ${ }^{13}$

Interestingly, despite its frequent utilization, the paper did not feature crystal light lemonade beverage (CLLB) as there

From Indiana University Department of Urology and Litholink Corporation, Laboratory Corporation of America ${ }^{\circledR}$ Holdings, Indianapolis, Indiana, USA. 
is little to no research on CLLB as an alternative source of alkali therapy. After multiple trials ${ }^{8-10}$ evaluating the effectiveness of lemon-based beverages, the results are still inconclusive; supporting continued efforts to find alternative sources of dietary citrate and alkali therapy. One example is the use of novel low-calorie OJ drinks with the potential to provide dietary citrate or alkali without large quantities of sugar.

Our group decided to evaluate the potential for urinary citrate and $\mathrm{pH}$ with low-calorie OJ beverages. Before any clinical application of low-calorie OJ in stone patients, we wanted to evaluate the alkali potential in popular consumer beverages; these included low-calorie OJ and CLLB. We hypothesized that low-calorie OJ and CLLB would have favorable alkali potential based on ion chromatography. After identifying beverages with favorable profiles based on ion chromatograph that were easily accessible and cost effective, we hypothesized that consumption of these specific beverages by healthy volunteers would yield urinary alkalization with concomitant increases in urinary citrate.

\section{Methods}

Using an ICS 2000 system equipped with an AS-11 analytical column with $\mathrm{KOH}$ elutent (Dionex, Sunnyvale, CA), ion chromatography was completed on common consumer beverages to evaluate for total citrate, malate, and alkali potential. The $\mathrm{pK}$ values of tricarboxylic acid citrate used to calculate anion content were 3.1, 4.7, and 6.4, and those for dicarboxylic malate were 3.4 and 5.1, respectively. Anion peaks were detected by a conductivity meter with eluent background conductivity suppressed by an ASRS ${ }^{\circledR}$ Ultra II anion self-regenerating suppressor. The $\mathrm{pH}$ of each beverage was measured with a $\mathrm{pH}$ electrode. Various brands of standard and low-calorie OJ, crystal light lemon and orange, and carbonated flavored water were selected for the initial analysis. Unprotonated citrate and malate anion concentrations were obtained and used to calculate the total alkali content of each beverage expressed in $\mathrm{mEq} / \mathrm{L}$.

From the initial analysis, two low-calorie OJ options [Tropicana 50 (TRP50) and Kroger low-calorie OJ (KLCO) brand] along with CLLB were selected for clinical evaluation. All of the commercial orange beverages had robust concentrations of alkali; however, TRP50 was chosen because it is widely available for purchase at stores such as Target, Walmart, and on Amazon.com. KLCO was selected because it was locally available and the cheapest option of low-calorie OJ options. CLLB was included as a zero-calorie option for those who might not tolerate the extra calories of even low-calorie OJ. The study was structured as a randomized prospective crossover study that evaluated the 24-hour urine parameters of 10 healthy volunteers (mean age: 42.1 [24-64] years, body mass index $25.3 \pm 4.1 \mathrm{~kg} / \mathrm{m}^{2}, 5 \mathrm{fe}-$ male) with no history of kidney stones. The volunteers were recruited through word of mouth, and flyers posted around the hospital after the study received institutional review board approval. Each volunteer was assigned a randomized drink order, which included the following: $2 \mathrm{~L}$ water/day, $1 \mathrm{~L}$ low-calorie TRP50 OJ and $1 \mathrm{~L}$ water/day, $1 \mathrm{~L} \mathrm{KLCO}$ and $1 \mathrm{~L}$ water/day, or $1 \mathrm{~L}$ CLLB and $1 \mathrm{~L}$ water/day. Each beverage was consumed for seven continuous days. Validation that volunteers were not consuming vitamins or medications that would affect their 24-hour urinalysis occurred upon enrollment. No other dietary restrictions were enforced. After 7 days of each beverage consumption, a 24-hour urine collection was completed and sent to Litholink Corporation for testing. Between each trial beverage, there was a 1-week washout period where volunteers had no dietary restrictions. The trial took 8 weeks to complete for each volunteer. The Litholink urinary panel provides measures including, but not limited to, citrate, calcium, oxalate, phosphate, uric acid, and urinary $\mathrm{pH}$. Volunteers maintained a diary where they recorded adherence to the beverage consumption requirements, any SEs from the beverages, and a description of their meals while on a trial week. These journals were reviewed at the conclusion of the trial to ensure consistency in dietary habits between the trial weeks and compliance with beverage consumption at the prescribed volumes. Paired changes in mean citrate excretion, $\mathrm{pH}$, and urine volume were the primary endpoints of the study and were conducted using an analysis of variance comparison of means. A $p$-value of $<0.05$ is considered statistical significant.

\section{Results}

Results of the chemical analysis are represented in Table 1. We found that Minute Maid pure Squeeze 50 had the highest citrate composition $(45 \mathrm{mmol} / \mathrm{L})$ of all the beverages analyzed, while LaCroix Orange $(<0.2 \mathrm{mmol} / \mathrm{L})$ and Crystal Light Orange $(15.5 \mathrm{mmol} / \mathrm{L})$ had the lowest. All the OJ drinks provided a large total alkali and potassium load. CLLB

Table 1. Results from Ion Chromatography on Common Consumable Beverages Completed WiTh THE Assistance of Litholink LAB CORP

\begin{tabular}{|c|c|c|c|c|c|c|c|}
\hline & $p H$ & $\begin{array}{c}\text { Citrate } \\
(\mathrm{mmol} / \mathrm{L})\end{array}$ & $\begin{array}{c}\text { Malate } \\
(\mathrm{mmol} / \mathrm{L})\end{array}$ & $\begin{array}{c}\text { Total Alk } \\
(m E q / L)\end{array}$ & $\begin{array}{c}K \\
(\mathrm{mmol} / \mathrm{L})\end{array}$ & $\begin{array}{c}\text { Sugar } \\
(g / L)\end{array}$ & $\begin{array}{c}\text { Calories } \\
\text { Liter }\end{array}$ \\
\hline Crystal light orange & 3.246 & 15.5 & $<0.2$ & 9.1 & $<2$ & 0 & 10 \\
\hline Crystal light lemonade & 3.218 & 30.4 & $<0.2$ & 17.3 & 6.4 & 0 & 10 \\
\hline $\begin{array}{l}\text { Minute maid pure squeezed } \\
50 \text { calories, no pulp }\end{array}$ & 3.964 & 45.2 & 8.6 & 52.8 & 53.4 & 42 & 208 \\
\hline Trop50, no pulp & 3.894 & 37.4 & 24.7 & 56.1 & 51.6 & 42 & 208 \\
\hline Trop50, some pulp & 3.824 & 37.1 & 23.5 & 57.6 & 48.5 & 42 & 208 \\
\hline LaCroix orange & 5.200 & $<0.2$ & $<0.2$ & & & 0 & 0 \\
\hline Tropicana, no pulp & 3.903 & 42.8 & 18.4 & 56.4 & 51.9 & 96.1 & 458 \\
\hline $\mathrm{KLCO}$ & 3.978 & 41.8 & 6.6 & 47.9 & 26.3 & 37.5 & 250 \\
\hline Simply orange, pulp & 3.924 & 42.6 & 19.4 & 63.5 & 52.9 & 85 & 667 \\
\hline
\end{tabular}

$\mathrm{KLCO}=$ Kroger low-calorie orange juice; $\mathrm{OJ}=$ orange juice. 
Table 2. Averages of 24-Hour Urinalysis for Common Urinary Parameters for Each Beverage

\begin{tabular}{lcccc}
\hline & Control & CLLB & KLCO & TRP50 \\
\hline Number of participants & 10 & 10 & 10 & 9 \\
Volume (L/day) & $2.5 \pm 1.2$ & $2.7 \pm 1.1$ & $2.9 \pm 1.3$ & $2.2 \pm 1.0$ \\
Calcium (mg/day) & $178 \pm 101$ & $189 \pm 71$ & $148 \pm 61$ & $184 \pm 114$ \\
Oxalate (mg/day) & $38.5 \pm 11.4$ & $36.8 \pm 7.7$ & $46.4 \pm 8.2$ & $42.2 \pm 18.3$ \\
Citrate (mg/day) & $735 \pm 294$ & $891 \pm 424$ & $913 \pm 422$ & $\mathbf{6 . 6 3} \pm \mathbf{0 . 4 2}$ \\
pH & $\mathbf{6 . 1 9} \pm \mathbf{0 . 4 5}$ & $\mathbf{6 . 4 4} \pm \mathbf{0 . 3 3}$ & $\mathbf{6 . 9 3} \pm \mathbf{0 . 4 1}$ & $0.68 \pm 0.34$ \\
Uric acid (g/day) & $0.71 \pm 0.24$ & $0.66 \pm 0.15$ & $0.65 \pm 0.28$ & $140 \pm 68$ \\
Sodium (mmol/day) & $180 \pm 93$ & $182 \pm 60$ & $187 \pm 79$ & $94.2 \pm 52.2$ \\
Potassium (mmol/day) & $79.3 \pm 21.8$ & $78.1 \pm 30.3$ & $104.1 \pm 42.1$ & $33.2 \pm 13.3$ \\
Ammonium (mmol/day) & $47.7 \pm 18.6$ & $42.3 \pm 12.6$ & $32.2 \pm 17.5$ & $110 \pm 46$ \\
Magnesium (mg/day) & $118 \pm 55$ & $111 \pm 34$ & $0.97 \pm 27$ & $1.01 \pm 0.39$ \\
Phosphorus (g/day) & $1.15 \pm 0.41$ & $0.94 \pm 0.33$ & $42.4 \pm 25.1$ & $49.4 \pm 33.1$ \\
Sulfate (mEq/day) & $55.8 \pm 24.3$ & $49.7 \pm 23.1$ & $25.5 \pm 3.2$ & $26.1 \pm 6.6$ \\
Creatinin24/kg (mg/kg/day)—male & $25.1 \pm 4.2$ & $26.4 \pm 2.3$ & $19.4 \pm 4.1$ & $22.7 \pm 6.1$ \\
Female & $22.5 \pm 4.2$ & $23.8 \pm 2.7$ & & \\
\hline
\end{tabular}

Statistical significance set at $p<0.05, \mathrm{pH}$ (bolded) was the only variable that showed statistical significance between the groups on ANOVA.

ANOVA $=$ analysis of variance; $C L L B=$ crystal light lemonade beverage; TRP50 $=$ Tropicana 50.

demonstrated an intermediate alkali load with $17.3 \mathrm{mEq} / \mathrm{L}$. In Table 2, 24-hour average urine results are listed by drink category. All collections were evaluated for their appropriateness $(\mathrm{Cr} 24 / \mathrm{kg})$ with average baseline values of $25.8 \pm 3.8$ and $22.1 \pm 3.6$, respectively, for male and female volunteers. The only statistical difference between the groups was change in urinary pH (CLLB, 0.25 [0.08-0.53]; KLCO, 0.74 [0.41-1.07 $p<0.05]$; TRP50, 0.25 [0.25-0.64]) with urinary citrate increased (CLLB, 116.6 [ -118 to 373; KLCO, 177.9 [ -3 to 359]; TRP50, $155.6[-4$ to 237$] \triangle \mathrm{mg} /$ day $[95 \%$ confidence interval]) by not statistically significant in a paired-difference test (Table 3). Changes in urinary volume, citrate, and urinary pH with TRP50 compared with KCLO were less; likely the result of a reduced beverage consumption at high volumes from gastrointestinal SEs potentially a result, in part, by the artificial sweetener. Volunteers reported SEs (-90\%), including gastrointestinal SEs (bloating, diarrhea, and acid reflux) and headaches with TRP50, which were less prevalent $(30 \%)$ and severe with KLCO. Intestinally, other than three patients complaining of the taste, no one reported any SEs associated with CLLB consumption. All participants validated that they were compliant with the volume of water and trial beverage for the trial week, with the exception of one participant who could not complete a week of TRP50 because of headaches and abdominal cramping. CLLB did raise urinary $\mathrm{pH}$ by $0.25(p=0.99)$, urinary volume $\sim 200 \mathrm{~mL}$ $(p=0.008)$, and citrate levels $155 \mathrm{mg} /$ day $(p=0.05)$ compared with values obtained during the water phase.

\section{Discussion}

Dietary sources of alkali and citrate have been identified. Common consumer beverages have been primarily evaluated because they have more consistent concentrations of bioavailable alkali salts and they provide the potential to increase dietary fluid intake. The AUA guidelines clearly outline that patients being treated for hypocitraturia or aciduria can reduce their risk of recurrent calcium oxalate or uric acid stone disease with supplemental citrate and alkali therapy. ${ }^{2}$ kcit has long been the mainstay therapy to restore urinary citrate and $\mathrm{pH}$ levels. ${ }^{14}$ However, there are a number of challenges associated with kcit therapy that negatively impact patient compliance. The typical dose of kcit ranges from 20 to $60 \mathrm{mEq} /$ day, which a recent publication estimated to cost up to $\$ 5100$ annually. ${ }^{15}$ For most patients, this is unaffordable, especially when insurance denies coverage. The prevalence of stones in the United States is increasing, ${ }^{16}$ and preventative therapies are paramount to minimize patient morbidity and mitigate health costs. Finding a dietary alternative, especially in a beverage, is imperative to reduce or replace our dependence on costly prescriptionbased medications with known patient compliance issues.

Table 3. Average of the Paired Difference Between Trial Beverage and Control

\begin{tabular}{|c|c|c|c|c|c|c|c|}
\hline & $\triangle \operatorname{Vol}(m L)$ & $\begin{array}{c}\triangle \mathrm{Ca} 24 m g \\
(m g / \text { day })\end{array}$ & $\begin{array}{c}\triangle O x 24 \\
(m g / \text { day })\end{array}$ & $\begin{array}{c}\triangle \text { Cit } 24 \\
(m g / \text { day })\end{array}$ & $\triangle p H$ & $\begin{array}{c}\triangle N a 24 \\
(m m o l / d a y)\end{array}$ & $\begin{array}{c}\triangle K 24 \\
(m m o l / d a y)\end{array}$ \\
\hline CLLB $(n=10)$ & 196 & 11.6 & -1.71 & 155.65 & +0.25 & 2.87 & -1.22 \\
\hline $\operatorname{KLCO}(n=10)$ & $387^{\mathrm{a}}$ & -29.43 & 7.90 & $177.98^{\mathrm{a}}$ & +0.74 & 7.10 & 24.28 \\
\hline TRP50 $(n=9)$ & -341 & 11.88 & 5.84 & 116.6 & +0.25 & -15.67 & 15.01 \\
\hline $\mathrm{P}$ significance & 0.080 & 0.212 & 0.452 & 0.863 & 0.033 & 0.691 & 0.217 \\
\hline
\end{tabular}

Statistical significance set at $p<0.05$, change $\mathrm{pH}$ (bolded) was the only variable that showed statistical significance between the groups on ANOVA. $\triangle$ represents change in.

${ }^{\mathrm{a}}$ When KCLO is compared with TRP50 for $\triangle \mathrm{Vol}(\mathrm{mL}) p=0.012$ and for $\triangle \mathrm{Cit} 24(\mathrm{mg} /$ day) $p=0.011$. 


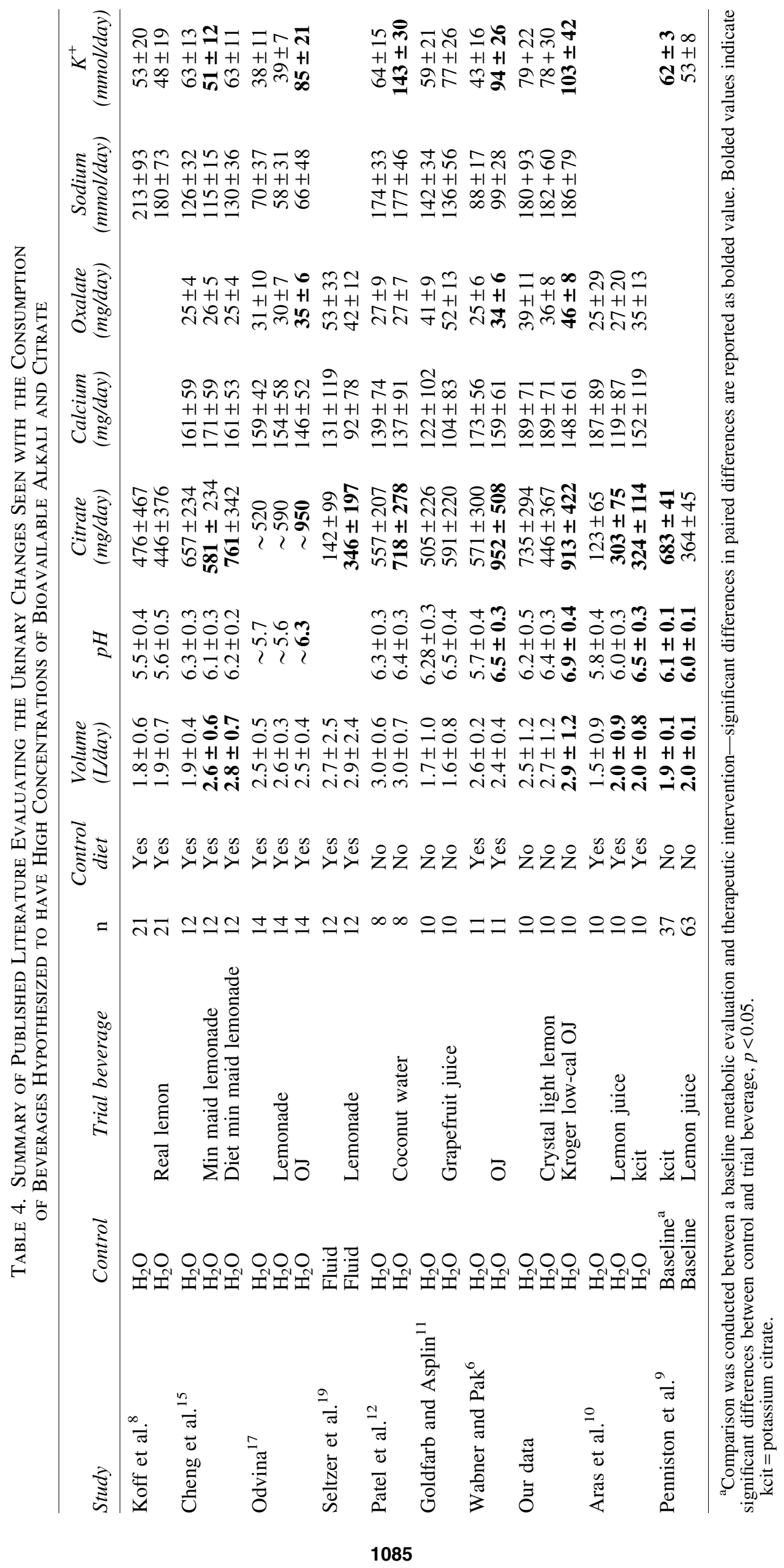


The early evidence that OJ has good alkali potential compared with alternate beverages ${ }^{6}$ has largely been overlooked because of valid concerns about the associated sugar and caloric content. To some extent, this aided in the proliferation of lemon-based beverage studies. Lemon-based beverages can be consumed in large volumes, and they avoid the introduction of stone substrates such as ascorbic acid. However, lemonade and lemon-based beverages have had mixed results ${ }^{8,10,15}$ with urinary citrate modulation or urine alkalization in healthy volunteers or recurrent stone formers (Table 4). A recent publication by Eisner and colleagues explains that dietary citrate exists as a salt coupled with potassium, calcium, sodium, magnesium, or as an acid. ${ }^{13}$ In the case of lemon-based beverages, the predominant cation is hydrogen, which neutralizes any systemic alkali potential from the conversion of citrate to bicarbonate by the liver. In addition, pure lemon juice has to be diluted to improve its palatability; factors that could be the reason for the variability in urinary citrate and $\mathrm{pH}$ modulation with lemon-based beverages. Despite a lower alkali content associated with CLLB compared with all OJ beverages on ion chromatography (Table 1), we did see increases in citrate, urine volume, and urinary $\mathrm{pH}$ in healthy volunteers from baseline levels on 24-hour urinalyses with CLLB. Even though the statistical significance may be lacking, our results do align with previous publications (Table 4) that in a paired-difference analysis, CLLB, on average, raised urinary volume, citrate, and $\mathrm{pH}$ compared with baseline.

By comparison, in addition to raising urinary citrate and volume, KCLO did show a statistically significant increase in average paired difference of urinary $\mathrm{pH}$. Wabner and Pak demonstrated the same finding in $1993^{6}$ with standard OJ, which was further supported by Odvina in $2006^{17}$ (Table 4). These studies are limited, in that they used high volumes of pure $\mathrm{OJ}$ in a controlled environment and dietary regimen that confers large dietary sugar loads and somewhat unrealistic lifestyle expectations of patients. The volunteers in this study demonstrated that consumption of KLCO can raise the urinary $\mathrm{pH}$, with less sugar, within the stresses of daily life and activity. Based on the average paired difference of $0.74 \mathrm{pH}$ units between baseline and KCLO urine samples, KCLO could be implemented into the prevention of uric acid or calcium oxalate stones in patients with aciduria. There are challenges with this intervention, both our data and those of Odvina showed increases in urinary oxalate likely resulting from higher dietary consumption of ascorbic acid (Table 4); however, these have limited clinical impact and can potentially be mitigated with increased dietary calcium consumption and avoidance of specific foods rich in oxalate. In addition, based on diary logs, $30 \%$ of volunteers had GI SE (two described bloating and one suffered abdominal cramps) from consuming KLCO. Although there were no compliance issues with the daily consumption of $1 \mathrm{~L}$ of KLCO, we did see issues with TRP50. Multiple volunteers (90\%) reported SEs with TRP50, which we hypothesized was caused by the artificial sweetener $\left(\right.$ Stevia $\left.{ }^{\circledR}\right)$ resulting in one patient withdrawing from the TRP50 trial week. We feel that there is a clinical application of low-calorie OJ in the prevention of nephrolithiasis; however, a specific type and possibly lower daily volume may be required before formal recommendations can be established.

The concerns over our dependence on kcit as the primary source for alkali and citrate are prompting multiple parallel studies of dietary alternatives. ${ }^{18,19}$ Aside from lemon- and orange-based beverages, other drinks, including grapefruit juice and coconut water, have shown similar changes in urinary citrate and $\mathrm{pH}$ after controlled consumption in healthy volunteers. $^{11,12}$ Compared with controls, after 4-7 days of grapefruit juice or coconut water consumption, urinary $\mathrm{pH}$ and citrate did increase, but these changes were all nonsignificant except for the increase in urinary citrate concentration after coconut water consumption (Table 4). By comparison, all beverage trials that used OJ (including this study for $\mathrm{pH}$ ) showed statistical increases in urinary $\mathrm{pH}$ and citrate after 7 days of consumption (Tables 3 and 4). Concerns over the sugar, ascorbic acid, and artificial sweetener load with the consumption of low-calorie OJ on overall gut microbiome health, stone metabolite absorption, and any underlying metabolic syndrome will persist with the use of OJ; however, a better alternative to increase urinary $\mathrm{pH}$ is still lacking. For example, Lytholyte ${ }^{\circledR}$ asserts $45 \mathrm{mEq}$ of alkali therapy for $\$ 2.25$ per day ${ }^{18}$ with no guaranteed fluid volume consumption compared with KCLO, which confers an average increase of $400 \mathrm{~mL}$ of urine at $\$ 1.46$ per day for the same amount of alkali. To providers, we would recommend trying different brands of low-calorie OJ if patients report poor palatability. The findings reported here are promising, but further studies are needed to evaluate if daily lowcalorie OJ is safe to consume in patients with a history of nephrolithiasis, hypocitraturia, aciduria, and potentially metabolic syndrome.

This study is not without limitations. Despite being a prospective randomized, crossover trial, the sample size of volunteer participants is small. Nevertheless, we were able to demonstrate a statistical difference in urinary $\mathrm{pH}$ when volunteers consumed KLCO. We realize that in the study design we did not control diet, environment, and activity; however, we did review the volunteer journals and could not identify any noteworthy variances in beverage compliance or diet variability among the volunteers. We feel this study design is still representative of how urinary modulation can be achieved despite the inherent variability when research is conducted in a real-world setting. In addition, the external validity of our results may have a limited potential when applied to patients with hypocitraturic or aciduric nephrolithiasis. These patients typically have comorbidities, for instance, metabolic syndrome, which may limit their ability to safely consume daily low-calorie OJ because of the additional sugar intake. In addition, it is unclear in a diseased state such as hypocitraturic nephrolithiasis with comorbidities such as metabolic syndrome as to how low-calorie OJ consumption will translate into systemic or urinary alkalinization. Further research is underway to evaluate the potential positive urinary changes daily low-calorie OJ consumption can have in patients with hypocitraturic or aciduric nephrolithiasis.

\section{Conclusion}

There are a variety of options to introduce natural sources of alkali and citrate salts into the diet. In healthy volunteers, our study supports the use of both low-calorie OJ and CLLB to modulate urinary characteristics; namely urinary $\mathrm{pH}$. Additional work is underway to evaluate if the same outcomes can be achieved in patients with nephrolithiasis, hypocitraturia, and low urinary $\mathrm{pH}$. 


\section{Author Disclosure Statement}

Dr. A.K. is a consultant for Boston Scientific Corporation, Lumenis and Cook Medical. J.R.A. is an employee of Litholink Corp.

\section{Funding Information}

This project was funded by the AUA Scholars Award program

\section{References}

1. Kursh ED, Resnick MI. Dissolution of uric acid calculi with systemic alkalization. J Urol 1984;132:286-287.

2. Pearle MS, Goldfarb DS, Assimos DG, et al. Medical management of kidney stones: AUA guideline. J Urol 2014;192:316-324.

3. Jendle-Bengten $\mathrm{C}$, Tiselius HG. Long-term follow-up of stone formers treated with a low dose of sodium potassium citrate. Scand J Urol Nephrol 2000;34:36-41.

4. Coe F. Price of Potassium Citrate 2014 [updated September 23rd]. Available from: https://kidneystones.uchicago.edu/ price-of-potassium-citrate/ Accessed March 1, 2020.

5. Thompson D. What's behind the Sharp Rise in Prescription Drug Prices? CBS News Healthday2016 [updated August 24]. Available from: www.cbsnews.com/news/whats-behindthe-sharp-rise-in-prescription-drug-prices/.

6. Wabner CL, Pak CY. Effect of orange juice consumption on urinary stone risk factors. J Urol 1993;149:1405-1408.

7. Penniston KL, Nakada SY, Holmes RP, et al. Quantitative assessment of citric acid in lemon juice, lime juice, and commercially-available fruit juice products. J Endourol 2008;22:567-570.

8. Koff SG, Paquette EL, Cullen J, et al. Comparison between lemonade and potassium citrate and impact on urine $\mathrm{pH}$ and 24-hour urine parameters in patients with kidney stone formation. Urology 2007;69:1013-1016.

9. Penniston KL, Steele TH, Nakada SY. Lemonade therapy increases urinary citrate and urine volumes in patients with recurrent calcium oxalate stone formation. Urology 2007; 70:856-860.

10. Aras B, Kalfazade N, Tuğcu V, et al. Can lemon juice be an alternative to potassium citrate in the treatment of urinary calcium stones in patients with hypocitraturia? A prospective randomized study. Urol Res 2008;36:313.

11. Goldfarb DS, Asplin JR. Effect of grapefruit juice on urinary lithogenicity. J Urol 2001;166:263-267.

12. Patel RM, Jiang P, Asplin J, et al. V. Coconut water: An unexpected source of urinary citrate. Biomed Res Int 2018; 2018:3061742.
13. Eisner BH, Asplin JR, Goldfarb, et al. Citrate, malate and alkali content in commonly consumed diet sodas: Implications for nephrolithiasis treatment. J Urol 2010;183: 2419-2423.

14. Barcelo P, Wuhl O, Servitge E, et al. Randomized doubleblind study of potassium citrate in idiopathic hypocitraturic calcium nephrolithiasis. J Urol 1993;150:1761-1764.

15. Cheng JW, Wagner H, Asplin JR, et al. The effect of lemonade and diet lemonade upon urinary parameters affecting calcium urinary stone formation. J Endourol 2019; 33:160-166.

16. Scales Jr. CD, Smith AC, Hanley JM, et al. Urologic diseases in America Project. Prevalence of kidney stones in the United States. Eur Urol 2012;62:160-165.

17. Odvina CV. Comparative value of orange juice versus lemonade in reducing stone-forming risk. Clin J Am Soc Nephrol 2006;1:1269-1274.

18. Stern KL, Canvasser N, Borofsky et al. Alkalinizing agents: A review of prescription, over-the-counter, and medical food supplements. J Endourol 2020;34:1-6.

19. Seltzer MA, Low RK, McDonald, et al. Dietary manipulation with lemonade to treat hypocitraturic calcium nephrolithiasis. J Urol 1996;156:907-909.

Address correspondence to: Amy Krambeck, MD Department of Urology Indiana University/IU Health Physicians 1801 Senate Boulevard; Suite 220 Indianapolis, IN 46202

USA

E-mail: akrambeck@iuhealth.org

$$
\begin{aligned}
& \text { Abbreviations Used } \\
\triangle & =\text { change in } \\
\text { AUA }= & \text { American Urologic Association } \\
\text { CLLB }= & \text { crystal light lemonade beverage } \\
\mathrm{kcit}= & \text { potassium citrate } \\
\mathrm{KLCO} & =\text { Kroger low-calorie orange juice } \\
\mathrm{L} & =\text { liter } \\
\mathrm{mEq} & =\text { milliequivalents } \\
\mathrm{OJ} & =\text { orange juice } \\
\mathrm{SE} & =\text { side effect } \\
\text { TRP50 } & =\text { Tropicana } 50 \text { Orange Juice }
\end{aligned}
$$

